\title{
AVALIAÇÃO DAS POTENCIALIDADES DOS CURSOS ONLINE ABERTOS E MASSIVOS (MOOCS): FORMAÇÃO DOCENTE COLABORATIVA EM REDE
}

\author{
Fabiana Soares Dos Santos Poschi ${ }^{1}$ \\ Sandra Dutra Piovesan ${ }^{2}$
}

RESUMO: O estudo versa sobre a modalidade de curso MOOCs (Cursos Online Abertos e Massivos) com foco em conhecer suas potencialidades para a formação continuada de docentes acadêmicos, inserindo estes em um sistema de educação colaborativa e em rede. A pesquisa aponta as características dos MOOCs, os fundamentos da criação, às relações entre adesão, complexidade e conectivismo nestes ambientes de aprendizagem; e verifica o que a literatura científica revela sobre o predomínio da inteligência coletiva no desenvolvimento dos MOOCs. Utiliza método de revisão integrativa de literatura, um estudo do tipo descritivo-exploratório, de abordagem qualitativa. O estudo concluiu que o contexto dos MOOCs favorece experiências mediadas, devido o alargamento das dimensões espaçostemporais de comunicação entre os indivíduos. Positiva-se a hipótese destacada que os MOOCs são instrumentos eficazes para o desencadeamento de uma aprendizagem cooperativa, favorecendo a democratização do conhecimento, e o exercício da inteligência coletiva no domínio educativo.

Palavras-chave: Aprendizagem colaborativa. Formação continuada. Conectiviso.

ABSTRACT: The study deals with the modality of MOOCs course (Open and Massive Online Courses) with a focus on knowing their potential for the continuing education of academic teachers, inserting them in a collaborative and networked education system. The research points out the characteristics of MOOCs, the foundations of creation, the relationships between adherence, complexity and connectivism in these learning environments; and it verifies what the scientific literature reveals about the predominance

\footnotetext{
I Professora de Educação Infantil, séries iniciais e de Língua Portuguesa na Educação de Jovens e Adultos EJA. Graduada em Letras/Espanhol e Respectivas Literaturas pelo Centro Universitário da Região da Campanha -URCAMP, pós-graduada em Mídias na Educação pela Universidade Federal de Santa Maria - UFSM, mestranda no Curso de Mestrado Acadêmico em Ensino pela Universidade Federal do Pampa -UNIPAMPA (Campus Bagé RS). Orcid:https://orcid.org/oooo-ooor-6939-5133. Lattes: http://lattes.cnpq.br/8577754176214206. Email: fabyysoares2or4@gmail.com.

${ }^{2}$ Doutora em Informática em Educação. Possui graduação em Ciência da Computação pela Universidade de Cruz Alta (2006), graduação em Programa Especial de Graduação e Formação de Professores pela Universidade Federal de Santa Maria, equivalente a Licenciatura em Computação (2012), Mestrado em Informática pela Universidade Federal de Santa Maria (20II) e Doutorado em Informática na Educação pela Universidade Federal do Rio Grande do Sul (2015). Atualmente é pesquisadora da Universidade Federal de Santa Maria e da Universidade Federal do Rio Grande do Sul e professora na Universidade Federal do Pampa, curso de Engenharia de Computação e Mestrado em Ensino. Tem experiência na área de Ciência da Computação, atuando principalmente nos seguintes temas: Linguagem Formais e Autômatos, Educação à Distância, Informática na Educação e Ambientes Imersivos.. Orcid: https://orcid.org/oooo-ooo2-3175-867X. Email: sandrapiovesan@gmail.com.
} 
of collective intelligence in the development of MOOCs. It uses an integrative literature review method, a descriptive-exploratory study with a qualitative approach. The study concludes that the context of MOOCs favors mediated experiences; due to the broadening of the spatiotemporal dimensions of communication between individuals. The hypothesis highlighted is positive that MOOCs are effective instruments for triggering cooperative learning, favoring the democratization of knowledge, and the exercise of collective intelligence in the educational domain.

Keywords: Collaborative learning. Networking. Connectivism.

\section{INTRODUÇÃO}

Os Cursos Online Abertos e Massivos (MOOCs) são geralmente oferecidos por Plataformas Educacionais adequadas às imposições contemporâneas que implicam no saber aplicar o ensino a distância (EaD), em um, fazer e refazer educação gerenciando o conhecimento de forma dinâmica, criativa e atrativa. Implicam em uma gestão de conhecimento autônomo-coletivo, onde através do conectivismo é possível absorver todas as formas de saberes (UNBTV, 2015).

Diante deste contexto de inovação tecnológica, o estudo indaga até que ponto esta modalidade de curso poderia contribuir para uma educação colaborativa em rede? Aponta por hipótese que frente à emergência de qualificação de processos formativos do corpo docente de universidades, o MOOC revela-se como eficaz para o desencadeamento de uma aprendizagem cooperativa e dinâmica tendo a inteligência coletiva no domínio educativo como elemento que lhe garante efetividade. (RESENDE, 2016).

A adoção dos Cursos Abertos Massivos (MOOCs) é uma oportunidade de formação e capacitação, e transformação do ambiente educacional, na perspectiva do aprender e ensinar. Adotar os MOOCs equipara-se a dar lugar ao exercício de inteligência coletiva (RESENDE, 2016). Ocorre que o compartilhamento de conhecimentos em tempo real gera habilidades e competências tecnológicas. Para o contexto, a aprendizagem em rede estimula a capacidade criativa, a criticidade e a proatividade; implicando em uma postura inovadora das instituições de ensino e seus profissionais. Desta forma justifica-se a escolha do tema.

O estudo aponta por objetivo geral avaliar as potencialidades dos Cursos Online Abertos e Massivos (MOOCs), dando ênfase às possíveis contribuições a uma educação colaborativa em rede no contexto de formação continuada de professores. E, para alcançar o proposto, apresenta por objetivos específicos, conhecer pressupostos teóricos que 
fundamentam a criação versus a adesão aos MOOCs para formação em rede; verificar o que a literatura científica revela sobre o predomínio da inteligência coletiva no desenvolvimento dos MOOCs.

A pesquisa caracteriza-se como uma revisão integrativa de literatura, do tipo descritivo-exploratório, de abordagem qualitativa. Visto parte da leitura e releitura de vinte periódicos postados nas edições da revista EmRede, considerando um recorte temporal de 2014 a 2020 (seis anos).

O domínio da teoria que sustenta a discussão do presente estudo tem origem em trabalho de Mestrado, oferecido pela UNIPAMPA campus Bagé RS que esta em processo de qualificação.

\section{PARTICULARIDADES DO MÉTODO E DA COLETA DE DADOS}

Em busca de compreender quais são as potencialidades dos MOOCs na formação continuada de professores e ainda, de identificar até que ponto esta modalidade de curso poderia contribuir a uma educação colaborativa em rede, utilizou-se uma revisão bibliográfica sistemática integrativa, conhecida por pesquisa com bases em evidência; um método que subentende duas vertentes, uma do tipo narrativa e outra, uma revisão bibliográfica sistemática (ÂNIMA_EDUCAÇÃO, 2014)

Meta análise: o sistema de revisão integrativa observa como primeira etapa uma análise quantitativa, de onde se fez uma seleção de "artigos científicos" no portal da Revista EmRede, com conteúdo “disponíveis na íntegra", publicados em "português” considerando um recorte temporal de seis anos (2014 a 2020).

Revisão sistemática: depois de realizado o download da revista EmRede dentro do período observado, fez-se uma análise dos títulos; leitura dos resumos e das introduções e, selecionou-se os artigos que poderiam contribuir com o presente trabalho. Dentro deste processo consideraram-se os objetivos específicos como categorias de estudos a serem alcançadas.

Diante do exposto se selecionou vinte artigos para o presente estudo. Seguido de leitura e releitura de títulos, e análise dos resumos, observando saturação de dados, selecionou-se para o presente estudo: 3 (três) publicações do ano de 2014 que contribuíram 
para trazer elementos essenciais e potenciais do uso do ensino a distância para a troca de experiências pedagógicas entre docentes do ensino superior no sentido de qualificar práticas e metodologias. Os elementos considerados foram à cultura digital (que impulsiona a adesão, inovação e a adequação dos docentes a novas tecnologias de comunicação em tempo real). 2 (duas) publicações de 2015; 5 (cinco) artigos publicados em 2018; 4 (quatro) publicados em 2019 e 6 (seis) em 2020, dentre os quais a publicação de Marconi e Lacerda (2020) destacase por apresentar tema e objetivo similar proposto nesse trabalho. Considerando que a revista não apresenta publicações em 2021, o acervo encerra este estudo, com primazia.

Os MOOCs recentemente passaram a ser motivo de reflexão, tendo um artigo em 2018 (RIBEIRO e CATAPAN, 2018) e três em 2020 (MACHADO, 2020; MARCONI e LACERDA, 2020; SILVA e MUNHOZ, 2020), contudo importa refletir sobre a transição do ensino presencial ao online, e termos que emergem neste período, tais como EaD, ensino híbrido, cultura digital, conectivismo entre outros.

\section{RESULTADOS E DISCUSSÃO}

Esta seção foi elaborada considerando desenvolveu-se de forma alinhada aos objetivos específicos elencados na introdução. Assim, apresentam-se conceitos pertinentes ao contexto de ensino a distância - EaD e aponta-se as características dos MOOCs que concorda-se potencializam a modalidade de ensino como ferramenta adequada à formação continuada (permanente) em rede, ou seja, colaborativa.

Diante da leitura dos artigos selecionados na revista EmRede, apresenta-se conceitos tais como, EaD, ensino híbrido; Cultura Digital, Teoria social da mídia; comunicação mediada; apresentadas por os autores, no uso de citações (diretas e indiretas).

A educação a distância recebe estímulo na legislação, nos instrumentos: Decreto n. 5.622/2005 (que a caracteriza); e estabelece que: "Poder Público incentivará o desenvolvimento e a veiculação de programas de ensino a distância, em todos os níveis e modalidades de ensino, e de educação continuada" (BRASIL, 2005 apud BRANCO e ALMEIDA, 2018, p. 216). Tendo-se por definição de EaD "uma forma industrializada de ensinar e aprender. [...] um método racional de partilhar conhecimentos, habilidades e atitudes" (MACHADO, 2014, p.8I). 
Observa-se que atualmente a realidade da educação no Brasil, é hibrida, podendo contemplar uma atuação presencial, semipresencial e a distância. Contudo vem sendo prioritário o ensino na modalidade $\mathrm{EaD}$, visto as potencialidades das "tecnologias de informação e comunicação - TICs, principalmente as digitais" (NONATO; SALES; SARLY, 2019, p. I62). O EaD, trata-se de uma modalidade de ensino a distância, "um campo epistemológico no qual agregam- se, fundem-se e produzem-se teorias e conhecimentos sobre relações do ensinar e do aprender" (MOURA et al, 2015, p.155), esse sistema de ensino influencia no ingresso das sociedades a uma cultura digital.

O autor Alonso et al. (2014) apresenta como elemento contributivo versus significativo a este estudo, as importantes relações entre experiências mediadas que se dão em função do alargamento das dimensões espaços-temporais de comunicação entre os indivíduos, que caracterizam a cultura digital e fundamentam a comunicação mediada.

Do contexto da $\mathrm{EaD}$, emergem ambientes educativos e portais tais como plataformas Moodle; nos quais há o desenvolvimento do ensino, conhecidos por chats, fóruns de discussão, que compreende-se por instrumentos facilitadores, no contexto da comunicação e interação. (MACHADO, 2014).

Os instrumentos auxiliam na troca de experiência. Ainda neste ambiente,“[...] é preciso ir além da adoção de uma prática interdisciplinar que transcenda os limites disciplinares e conceituais do conhecimento. [...]. [...] também, incorporar no cotidiano educacional as novas Tecnologias da Comunicação e da Informação (TICs)”. (SANTOS e SILVA, 2020, p.49).

Dentro dos campos de estudo respectivos à prática de ensino, que cerca a perspectiva das possibilidades de aprendizagem, têm destaque as tecnologias móveis sem fio - TMSF (laptops, celulares, tablets) de onde surge o conceito de aprendizagem com mobilidade conhecida por m-learning, (VALENTE e ALMEIDA, 2014).

O ensino a distância com foco em ensino profissional teve sua oferta por edital e resultou na criação da Rede e-Tec Brasil, que recebeu regulamentação através do Decreto 7.589/2012. "O programa reafirma-se com a finalidade de desenvolver a educação profissional e tecnológica na $\mathrm{EaD}$, compreendida como estratégia de ascensão da escolaridade, tendo como preceito a permanência e a continuidade de estudos". (NASCIMENTO e RODRIGUES, 2018, p. 103). 
Os MOOCs, são modalidades de cursos que admitem o uso dos TMSF, diferenciando-se dos cursos em $\mathrm{EaD}$ em alguns pontos que tratam de: “[...] raramente possuem pré-requisito para alunos ingressantes, já que são ofertados em plataformas capazes de receber mais alunos. [...]" (SILVA e MUNHOZ, 2020, p.33).

As diferenças respectivas aos MOOCs e o $\mathrm{EaD}$, expandem-se visto que o $\mathrm{EaD}$, necessita de tutores, tem número limitados de vagas; em geral com custo; os MOOCs não necessitam de tutoria, alcançam grandes massas; em geal é ofertado gratuitamente, e não implica na oferta de certificados (não são necessariamente certificados), esta modalidade de curso pode ser ofertar cursos MBA, profissionalizante, de formação continuada dentre outros. Há ênfase na gestão de conhecimento autônoma, onde o aluno faz seu horário e tem seu ritmo próprio de aprendizagem.

$\mathrm{Na}$ coleta de conceitos pertinentes ao tema, que trata do estudo das potencialidades dos MOOCs como ferramentas de formação de professores, observou-se um reconhecimento de pressupostos teóricos que fundamentam a criação e a adesão aos MOOCs. No contexto referem-se à cultura digital que emerge da globalização, e do acirrado desenvolvimento de tecnologias de informação, que se relacionam ao conectivismo, um comportamento social, ou evento, que se traduz como sendo um processo de interação social (comunicação) desenvolvido no contexto de ensino online. Evidencia-se assim, que o conhecimento tem tomado corpo vivo, que se desenvolve de forma induzida às inovações tecnológicas, onde há um aprendizado em rede.

A globalização incidiu no surgimento de uma infinidade de ferramentas digitais, que tratam de aplicativos, programas, dispositivos entre outras tecnologias Alguns destes, tais como wikis, blogs, chats, fóruns, redes sociais, dentre outros auxiliaram na quebra de barreiras respectivas a informação, interação e colaboração entre diferentes sujeitos. Evidentemente que a forma de fazer educação sofrendo uma transição (de presencial, para semipresencial e por fim para o $\mathrm{EaD}$ ), onde teve-se "dentre outros benefícios, [...] um esforço maior para motivar a interatividade e a execução de trabalhos colaborativos, na rede" (SOUZA, 2019, p.173). Somando-se a este fator observa-se que: "Observa-se, assim, o encurtamento das distâncias e o espaço temporal, além de uma grande integração dos conhecimentos e saberes que se entrelaçam". (OLIVEIRA et al., 2015). 
Em consonância com o citado, e até mesmo reforçando os benefícios do ensino híbrido versus $\mathrm{EaD}$, lê-se que "a educação tem sido provocada a repensar e ressignificar suas práticas pelo uso conjuntivo de múltiplas tecnologias nos ambientes escolares, como recursos subsidiados para os processos de ensino-aprendizagem na era digital" (ANJOS; SILVA; ANJOS; 2019, p. 204) o que dá, um impulso; dinamismo e criatividade no fazer educação. Também estudos de Silva, Prado e Pasqualini (2019) referem que o EaD é um "recurso de incalculável importância, pois gera mais uma possibilidade de socialização do saber”. (SILVA; PRADO; PASQUALINI; 2019, p. 277).

Assim, diz-se que a introdução do ensino a distância - EaD, impulsionou diferentes sujeitos a uma nova postura, e deliberadamente tem sido um caminho para ampliar "habilidades operacionais em todos os domínios da atividade humana" (NASCIMENTO e SAINZ, 2020, p. 6)

É conhecido o déficit dos docentes com relação ao uso das tecnologias, mesmo em cursos de formação docente, havendo debates que impõem uma postura mais determinada à gestão e até que impliquem em desenvolvimento de Políticas Públicas. Contudo, "ao mesmo tempo em que a tecnologia transforma a sociedade, é por esta transformada, resultado dos diversos usos e aplicações que recebe" (NETO e MILL, 2018, p. I24).

O estudo de Marconi e Lacerda (2020, p.248) refere que a realidade docente na era digital implica em uma instrumentalização dos docentes, e os MOOCs podem, com sucesso, serem usados para estes fins. Da mesma forma observa-se que: "podem contemplar ações: de Qualificação Profissional, de Apoio a Aula Presencial, de Treinamento Corporativo, de oferta de EaD/Cursos Técnicos, de Graduação e Pós -graduação, de oferta de cursos de Extensão e Preparatórios”.(RIBEIRO e CATAPLAN, 2018, p.59).

A adesão aos MOOCs tem potencializado a democratização das tecnologias digitais "e vem alterando as práticas pedagógicas por meio dos usos e das apropriações das mídias aplicadas ao ensino, [...]. Essas didáticas digitais impactam nos processos de ensinoaprendizagem” (MACHADO, 2020, p. 273).

No campo de saberes em $\mathrm{EaD}$, discursa-se sobre os materiais didáticos disponíveis e as confecções próprias (de autoria) de onde observa-se que estes são essenciais para potencializar o processo de ensino-aprendizagem (JOYE et al., 2018 p. 150). 
A inteligência coletiva dos sujeitos envolvidos no processo de $\mathrm{EaD}$, e em especial nos MOOCs é evidenciada de muitas formas, e em diferentes perspectivas. Inicia-se na adesão a Cultura Digital, nesta a troca de saberes é realizada de forma dinâmica, natural, cada descoberta é compartilhada espontaneamente. Os aplicativos, e programas se disseminam rapidamente, e até mesmo os dispositivos recebem inovações constantes, de forma que o saber manusear estes é com certeza mérito da união, da rede, do conectivismo; da socialização experimentada em tempo real. Há, portanto, interatividade e colaboração em rede; troca de saberes para fins de instrumentalizar tanto os docentes quanto os discentes.

\section{CONSIDERAÇÕES FINAIS}

O trabalho revela que o contexto dos MOOCs favorece experiências mediadas; devido o alargamento das dimensões espaços-temporais de comunicação entre os indivíduos. Positiva-se a hipótese destacada que os MOOCs são instrumentos eficazes para o desencadeamento de uma aprendizagem cooperativa, favorecendo a democratização do conhecimento, e o exercício da inteligência coletiva no domínio educativo.

O conhecimento estando em contínua transformação, caracteriza-se como dinâmico, (tanto quanto a conteúdos, como no que refere a métodos, técnicas e, mais precisamente a tecnologias), promovem assim a gestão de conhecimento autônomo-coletivo.

Assim, conclui-se que há viabilidade no uso de MOOCs para fins de formação permanente de docentes, no sentido que estes ambientes admitem a efetivação de cultura digital, movida pelo conectivismo, onde há uma democratização do ensino. No campo do saber compartilhado, compreende-se que ele passa a não ser propriedade específica de um indivíduo, mas uma condição para o desenvolvimento de todos os envolvidos; o objeto que move o curso de formação é adquirir habilidades e competências tecnológicas em tempo de exercício.

Como contribuição sugere-se o aproveitamento dos MOOCs como espaço de troca de experiências, compartilhamento de saberes com poder de resolução diretamente voltado ao uso de métodos e tecnologias emergentes.

\section{REFERÊNCIAS}

ALONSO et al., K.M. Aprender e ensinar em tempos de cultura digital. Rev de Educação EmRede: Reflexões sobre teoria e prática em EaD. Porto Alegre, v.I, n.I, p. I52-I68. 2014. 
Disponível em: https://www.aunirede.org.br/revista/index.php/emrede /article/view/r6/28 Acesso em 30 jan. 2021.

ÂNIMA_EDUCAÇÃO, Grupo. Manual Revisão Bibliográfica Sistemática Integrativa: a pesquisa baseada em evidência. Ânima Educação, EAD - Educação a Distância, 2014. Disponível em: http://biblioteca.cofen.gov.br/wp-content/uploads/2o I9/o6/manual_revisao_bibliografica-sistematica-integrativa.pdf Acesso em 30 jan. 202I.

ANJOS, R.A.V; SILVA, L.M.; ANJOS, A.M. Ensino Híbrido: organização e sistematização de conceitos com base em revisão sistemática da literatura. Rev de Educação EmRede: Ensino Híbrido ou Blended Learning. Santa Catarina, v.6, n.2, p. 203-220. 2019. Disponível em: ahttps://www.aunirede.org.br/revista/index.php/emrede /article/view/467/458 Acesso em 30 jan. 202r.

BRANCO, J.C.S.; ALMEIDA, V. Dialogando sobre EaD: docência e gestão. Rev de Educação EmRede: Caminhos da autoria e criatividade na EaD. Santa Catarina, v.5, n.I, p. 215-231. 2018. Disponível em: https://www.aunirede.org.br/revista/index.php/ emrede/article/view/270/306 Acesso em 30 jan. 2021.

JOYE, C.R.; Material Didático para a EaD: Autoria e criatividade. Rev de Educação EmRede: Ensino Híbrido ou Blended Learning. Santa Catarina, v.5, n.I, p. 150-167. 2018. Disponível em: https://www.aunirede.org.br/revista/index.php/emrede/article/vie w/288/308 Acesso em 30 jan. 2021.

MACHADO, M.C. Dialogismo e autoria na educação à distância. Rev de Educação EmRede: Reflexões sobre teoria e prática em EaD. Santa Catarina, v.I, n.I, p. 79-9I. 2014. Disponível em: https://www.aunirede.org.br/revista/index.php/emrede/article/vie w/8/20 Acesso em 30 jan. 2021.

MACHADO, S.P. Oliveira Silveira: consciência negra em MOOC da Unipampa na Plataforma Lúmina da UFRGS. Rev de Educação EmRede: Responsabilidades e Desafios para a consolidação da EaD. Santa Catarina, v.7, n.2, p. 267-287. 2020. Disponível em: https://www.aunirede.org.br/revista/index.php/emrede/article/view/607 /590 Acesso em 30 jan. 2021.

MARCONI, K.; LACERDA, A.L. MOOC: diálogos sobre cultura digital e formação docente: uma ação de extensão universitária. Rev de Educação EmRede: Responsabilidades e Desafios para a consolidação da EaD. Santa Catarina, v.7, n.2, p. 248-266. 2020. Disponível em: https://www.aunirede.org.br/revista/index.php/emrede/ article/view/625/589 Acesso em 30 jan. 202I.

MOURA, A.C.O.S. et al. Formação docente para atuar na EaD: reflexões e propostas. Rev de Educação EmRede: Sujeitos, políticas, tecnologias e processos EmRede: produções do ESUD 2014, Santa Catarina, v.2, n.I, p. 155-167. 2015. Disponível em: https://www.aunirede.org.br/revista/index.php/emrede/article/view/39/47 Acesso em 30 jan. 2021.

NASCIMENTO, C.O.; RODRIGUES, S.C. Vozes que referenciam os Cursos Técnicos a Distância como uma conquista pessoal e profissional. Rev de Educação EmRede: Caminhos da autoria e criatividade na EaD. Santa Catarina, v.5, n.I, p. IO2-II2. 2018. Disponível https://www.aunirede.org.br/revista/index.php/emrede/article/view/286/ 284 Acesso em 30 jan. 202I.

NASCIMENTO, C.O.; SAINZ, R.L. Educação à distância - Teoria e prática. Rev de Educação EmRede: Responsabilidades e Desafios para a consolidação da EaD. Santa 
Catarina, v.7, n.2, p. o6-I4. 2020. Disponível em: https://www.aunirede.org.br/revista/ index.php/emrede/article/view/599/591 Acesso em 30 jan. 202I.

NETO, V.B.S.; MILL, D. Intensificação do trabalho docente e tecnologias digitais em pesquisa sobre Educação no Brasil. Rev de Educação EmRede: Caminhos da autoria e criatividade na EaD. Santa Catarina, v.5, n.I, p. 124-136. 2018. Disponível em: https://www.aunirede.org.br/revista/index.php/emrede/article/view/289/309 Acesso em 30 jan. 2021.

NONATO, E.R.S.; SALES, M.V.S; SARLY, C.R. Educação a Distância, hibridismos e metodologias ativas: fundamentos conceituais para uma proposta de modelo pedagógico na oferta das disciplinas semipresenciais dos cursos presenciais de graduação da UNEB. Rev de Educação EmRede: Ensino Híbrido ou Blended Learning. Santa Catarina, v.6, n.2, p. I62-17ı. 2019. Disponível em: https://www.aunirede.org.br/revista/index.php/ emrede/article/view/489/440 Acesso em 30 jan. 2021.

OLIVEIRA, A.S. et al. Docência compartilhada em EaD: reflexões sobre a formação docente. Rev de Educação EmRede: Sujeitos, políticas, tecnologias e processos EmRede: produções do ESUD 2014, Santa Catarina, v.2, n.I, p. 89-99. 2015. Disponível em: https://www.aunirede.org.br/revista/index.php/emrede/article/view/26/ 42 Acesso em 30 jan. 2021.

RESENDE, Ieda Maria de. As noções do conhecimento de Pierre Lévy e suas implicações na Educação. São Paulo, 2016 p.ı4o. (Tese de Mestrado) Programa de PósGraduação em Educação. Orientação Cristiane Maria Cornélia Gottschalk. Universidade de São Paulo. Faculdade de Educação. São Paulo, 2or6. Disponível em: https://www.teses.usp.br/teses/disponiveis/48/48134/tde-I81o2016142400/publico/CO RPO_REV.pdf Acesso em 30 jan. 202I.

RIBEIRO, L.O.M.; CATAPAN, A.H. Plataforma MOOC e Redes de Cooperação na EaD. Rev de Educação EmRede: Caminhos da autoria e criatividade na EaD. Santa Catarina, v.5, n.I, p. 46-62. 2018. Disponível em: https://www.aunirede.org.br/revista /index.php/emrede/article/view/297/3II Acesso em 30 jan. 2021

SANTOS, J.J.; SILVA, P.C. Formação docente em EaD voltada ao programa nascional de integração da educação profissional com a educação básica, na modalidade de Jovens e Adultos (PROEJA). Rev de Educação EmRede: Responsabilidades e Desafios para a consolidação da EaD. Santa Catarina, v.7, n.2, p. 47-6o. 2020. Disponível em: https://www.aunirede.org.br/revista/index.php/emrede/article/view/6rg/602 Acesso em 30 jan. 202I

SILVA, A.P.; PRADO, R.C.; PASQUALINI, E. Ambientes Hibridos de aprendizagem: entre a educação presencial e a educação à distância. Rev de Educação EmRede: Ensino Híbrido ou Blended Learning. Santa Catarina, v.6, n.2, p. 276-287. 2019. Disponível em: https://www.aunirede.org.br/revista/index.php/emrede/article/view/477 /463 Acesso em 30 jan. 2021.

SILVA, J.M.C.; MUNHOZ, E.M.B. O Processo de consolidação da EaD no IFRS por meio dos MOOCs e a apliação do acesso a educação. Rev de Educação EmRede: Responsabilidades e Desafios para a consolidação da EaD. Santa Catarina, v.7, n.2, p. 30-46. 2020. Disponível em: https://www.aunirede.org.br/revista/index.php/emrede/ article/view/546/593 Acesso em 30 jan. 2021.

SOUZA, M.C.S. A Hibridização como caminho para a inovação do ensino aprendizagem. Rev de Educação EmRede: Ensino Híbrido ou Blended Learning. Santa 
Catarina, v.6, n.2, p. 172-182. 2019. Disponível em: https://www.aunirede.org.br/revista/index.php/emrede/article/view/464/455 Acesso em 30 jan. 2021.

UNBTV, Canal Universitário de Brasília / Site da TV da Universidade de Brasília. MOOCs Conectivismo e a perda do poder do Professor. Eric Rabkin discutiu as perspectivas da educação para o futuro. 2015. Disponível em: http://www.unbfuturo.unb.br/artigos/93moocs-conectivismo-e-a-perda-do-poder-do-professor Acesso em o5 fev. 202I.

VAlENTE, J. A.; ALMEIDA, M.E.B. Narrativas Digitais e o Estudo de Contextos de Aprendizagem. Rev de Educação EmRede: Reflexões sobre teoria e prática em EaD. Santa Catarina, v.I, n.I, p. 32-5I. 2014. Disponível em: https://www.aunirede.org.br/revista/index.php/emrede/article/view/ro/22 Acesso em 30 jan. 2021. 